\title{
Innovative process engineering: a generic model of the innovation process
}

\author{
Thomas Penide $^{\mathrm{a}}$, Didier Gourc ${ }^{\mathrm{a} *}$, Hervé Pingaud ${ }^{\mathrm{a}}$ and Philippe Peillon ${ }^{\mathrm{b}}$ \\ ${ }^{a}$ Centre Génie Industriel, Université de Toulouse, Mines Albi, Albi, France; ${ }^{b}$ Pôle Innovation, PIERRE FABRE Laboratories, \\ Gaillac, France
}

\begin{abstract}
Innovation can be represented as a knowledge transformation process perceived with different levels of granularity. The milestones of this process allow assessment for its each step and set up feedback loops that will be highlighted. This innovation process is a good starting point to understand innovation and then to manage it. Best practices being patterns of processes, we describe innovation best practices as compulsory steps in our innovation process. To put into practice, the management of innovation in a concrete organisation, an alignment (in our case a mapping) between a repository of business processes and our typical innovation process, helps to describe which best practice applies to which business process.
\end{abstract}

Keywords: innovation; best practices; BPM; modelling; alignment

\section{Introduction}

Nowadays, globalisation exacerbates competition between companies. Customers are increasingly open to competition in their supplier's selection. This competition also enables customers to be more and more difficult to please with delivery time, cost and the required quality of products. Facing these requirements, companies from Asia and developing countries reveal themselves as leading competitors for mass production facility. Industrialised countries must change their activities to survive in the long-term perspective. In such a context, western industries strive to outdo their competitors, both in design and in industrialisation of new products, with a shorter lifecycle time. The work of OECD on innovation is a feature of this phenomenon. This organisation provides a clear definition of innovation in the Oslo Manual that covers the whole range of efforts, from ideas to sales (OECD 2005): "An innovation is the implementation of a new or significantly improved product (goods or service), or process, a new marketing method, or a new organisational method in business practices, workplace organisation or external relations'.

For example, European Community is involved in what is called the challenge of a 'knowledge economy' described in the 'Lisbon Strategy'. The European Union publishes an annual scoreboard of innovation, in which countries are ranked using several criteria of innovation (European Commission 2008). The works of the OECD and the European Union help to establish a culture of innovation and the creation of a new vision of innovation. A definition of innovation will be discussed further on. However, it is commonly known that innovation is seen not only as a necessary way to ensure the delivery of new products to the market by an enterprise, but also as an essential component in the daily management of organisations. This is especially true for start-up enterprises where innovation is the driving force of the initial growth. For others, innovation sounds like risk taking, sometimes causing companies a lot of problems. These problems are created by the reluctance of enterprises to innovate (Christensen 2003), or an obsession by the management to monitor only best management practices that are sometimes in conflict with innovation. In order to show such differences, Boly (2008) describes a set of best practices for innovation related to innovation activities and innovation managing activities.

Pharmaceutical industries are particularly sensitive to these questions and to the evolution that is about to happen if innovation management is becoming a common policy. For many years, a lack of innovation in this specific field has systematically led to a resurgence of mergers and to acquisitions (Duflos 2007). So nowadays, relevant industrial companies that want to remain independent put all their hopes for growth on the success of products from their research and development portfolio. Let us underline that managing innovation really seems crucial for companies that currently have to face very high project attrition rates. Hence, they support multiple 
concurrent projects at the research stage, leading to manage product and process development at the same time so that time to market could be shortened for successful project. Furthermore, the process development is necessary to meet the requirements of the regulation authorities for the marketing authorisation of these products. So, for all these reasons, developing an innovative molecule requires increasing investments throughout the project life. It makes management of the innovation process credible in this industry, as it could speed up the realisation of some project steps. Indeed, the development cost of a new chemical entity is estimated around US\$800 million (DiMasi et al. 2003).

A pharmaceutical company seems to be an appropriate case study, since our goal is to understand and describe relationships between innovation activities and innovation practices when innovation management is put into practice. Our research work has been supported by a feedback from experience in such a context. Details will be provided in Section 2.

Even if it has mainly considered current added values of companies, and focused on 'as is' to 'to be' transformations of business improvements, enterprise engineering is not really familiar with the concept of product/process/organisational innovation as a global management artefact. Enterprise engineering seems therefore to be a framework that needs to be adapted for such a subject into which uncertainty plays a major role. Management of innovative activities has been intensively studied recently. Results from that research provide a sound basis for progress in management science. Fertilisation of these results within an enterprise engineering framework still remains an original work that we try to investigate not only at a conceptual level but also at a practical one as explained before.

Sienou (2009) defines enterprise engineering as a rational approach for designing and implementing projects that improve the structure and the behaviour of organisations producing either goods or services. It develops solutions based on modelling of an organisation, especially modelling its business processes to ensure quality and consistency of all these projects. By similarity, it is possible to define innovation engineering as a creative approach for designing and implementing projects to promote novelty in organisations. A project delivers a final result that is typically something new, but the way to get it is not necessarily innovative. This definition introduces the distinctness between what could be considered as classical projects and what should be perceived as their specialisation into a class of innovative projects. A second assumption of our research work emerges from this position. We will try to describe this barrier thanks to a powerful tool, which is the modelling of the features of innovative projects inside the model of a classical project. Then, our research work supports this idea that innovation process management is a subject at the crossroad between innovation engineering and enterprise engineering.

We will also assume that modelling of innovative processes is able to sustain innovation engineering and ensures quality and consistency of all innovative projects. Consequently, management of innovation can be defined as a horizontal alignment between business processes and innovation processes. We will propose in this article a set of best practices which provides a foundation to this alignment.

To develop this management of innovation, the research work follows a bottom-up approach in three steps, starting from a particular case study. The context of this case study is presented in Section 5 . The first step of the research work is dedicated to the definition of the innovation process. As proposed before, this process is described at a conceptual and rather generic level using a modelling framework derived from the CIMOSA (Computer Integrated Manufacturing Open Systems Architecture) approach (Vernadat 1996). After a literature review (Penide et al. 2009), we validated a representation of innovation activities as a process, and we modelled a typical innovation process in a simple and generic way. This representation of the innovation process highlighted the operational, supporting and managing activities of the innovation process, and is developed in Section 2.

The next step shows how to use this innovation process to promote innovation. For that, best practices are introduced as 'patterns' of processes. Then, as it becomes possible to put innovation in the perspective of a business process repository of the company, the alignment takes the shape of a mapping between the business processes and the innovation process. This mapping will be a reference that aims to associate innovative best practices with business process. The framework of this alignment is detailed in Section 3.

In Section 4, a set of innovation best practices is described. Each practice will be associated with at least one innovation activity. Finally, Section 5 gives details and lessons learned about the implementation of our proposal in the specific context of the case study.

\section{The typical innovation process}

The innovation process has been firstly described as a linear process (Weelright and Clark 1992, Cooper 2001) generally beginning from an idea and finishing with the product launch (Ben Rejeb 2008). But MacGregor et al. (2006) identify that this process is more and more modelled as a process composed of feedback loops (Galanakis 2006, Boly 2008). We can 
consider that most of the proposed models tend to focus on a particular part of the innovation process, whether it is on operational (Cooper 2001, Cormican and O'Sullivan 2004, Roper et al. 2008), supporting (Boly 2008) or management activities (Cormican and O'Sullivan 2004, Boly 2008) of the innovation process. Let us remember that operational activities are characterised by the fact that they add value to inputs, while supporting activities are processes that do not participate directly in the added value generated by the operational processes, but contribute to it by providing resources. Management activities transform information into decisions in order to control operational activities. The whole innovation process can be described in a generic approach, from idea to innovation and from management to operational and supporting activities, using a business process management (BPM) framework and modelling languages such as IDEF0. Firstly, a focus is made on the operational activities of the innovation process so as to explain how the value is added. The definition provided by Roper et al. (2008) is chosen for this generic starting point. These authors present the innovation process as a knowledge transformation process using three major activities:

(1) A first activity of knowledge sourcing

(2) A second one of knowledge transformation into a physical innovation (new product or process)

(3) As the innovation of firms becomes a reality, a final stage is dedicated to the exploitation of innovation.

Some other elements have been added to Roper's definition on the basis of a literature synthesis (Penide et al. 2009). A representation into two levels of granularity is proposed:

- Level 1 is a macro-modelling of the innovation process.

- Level 2 is a more detailed process model introducing a clear separation into management, operational and supporting processes.

\subsection{The innovation macro-process}

The innovation macro-process highlights the relationship between the process and its environment. This generic innovation process model is shown in Figure 1 using the IDEF0 modelling language. Let us consider that it is a global process map.

This model and all the other ones that will be produced in this article are designed using a business process modelling tool, Aris Business Designer (IDS Scheer 2010).

The innovation process is primarily a knowledge transformation process. The main input is knowledge, relative to a problem. The problem to face is the trigger of the innovation process, as well as ideas and intentions that will irrigate this process. After execution of an innovation process, these inputs could deliver results like:

- Innovations

- New knowledge shared by the stakeholders

- Intellectual property.

The IDEF0 syntax of a business process model does not require an unconditional use of all inputs, or a production of all outputs (from left to right of the

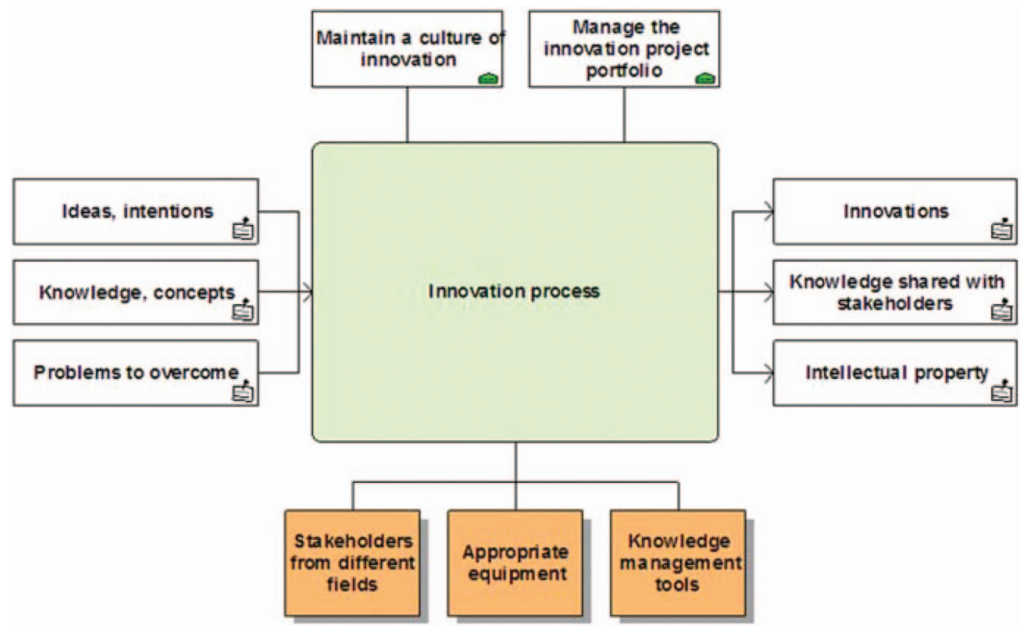

Figure 1. Innovation macro process. 
central box). For example, the process can be executed without creating intellectual property.

As described below the central box, the innovation process uses many resources to transform this knowledge, among which we highlight the following:

- Stakeholders from different fields and with different skills, internal or external to the organisation, trained, able to carry out this innovative approach

- Appropriate equipment to find ideas, to make products, prototypes or for tests

- Knowledge management tools that use, catch and provide knowledge for everyone.

The upper side of the central box is a set of objectives for the innovation process:

- Maintain a culture of innovation. This culture leads to an appropriation of the approach and issues by the stakeholders. It involves to develop best practices.

- Manage the innovation project portfolio. Indeed, innovations are produced by projects that coexist. A project portfolio management must organise the priorities on projects, and the selection of promising projects, in order to keep the organisation within acceptable limits in terms of resource management.

\subsection{Details of the innovation process}

Further details about the innovation process are given at a second level of granularity of the map. At this level, three complementary parts will be considered: management (in the upper rectangle), operational (in the middle rectangle) and supporting (in the bottom rectangle) processes (Figure 2). Only input and output streams of the operational activities are drawn for more readability. They are depicted with rectangles including a logo shaped like a document.

A stream of knowledge connects the operational activities. The first activity aims to define or redefine the problem that occurs, involving ideas, concepts or intentions that will help structure the work and suggest a problem formulation. Indeed, a new idea or an unsolved problem can be the trigger of the innovation process. The second activity uses the problem defined in order to provide knowledge. This knowledge is transformed in a new form of innovation. This new form of innovation is an invention chosen to be exploited in an innovation, intellectual property and knowledge shared by the stakeholders as described by Chen et al. (2010).

Activities are all interconnected by streams of information. Depending on the availability of relevant information, the activities are not sequential in time. They may work in parallel or be executed many times, for example. This process is a non-linear one but is composed of feedback loops described in each

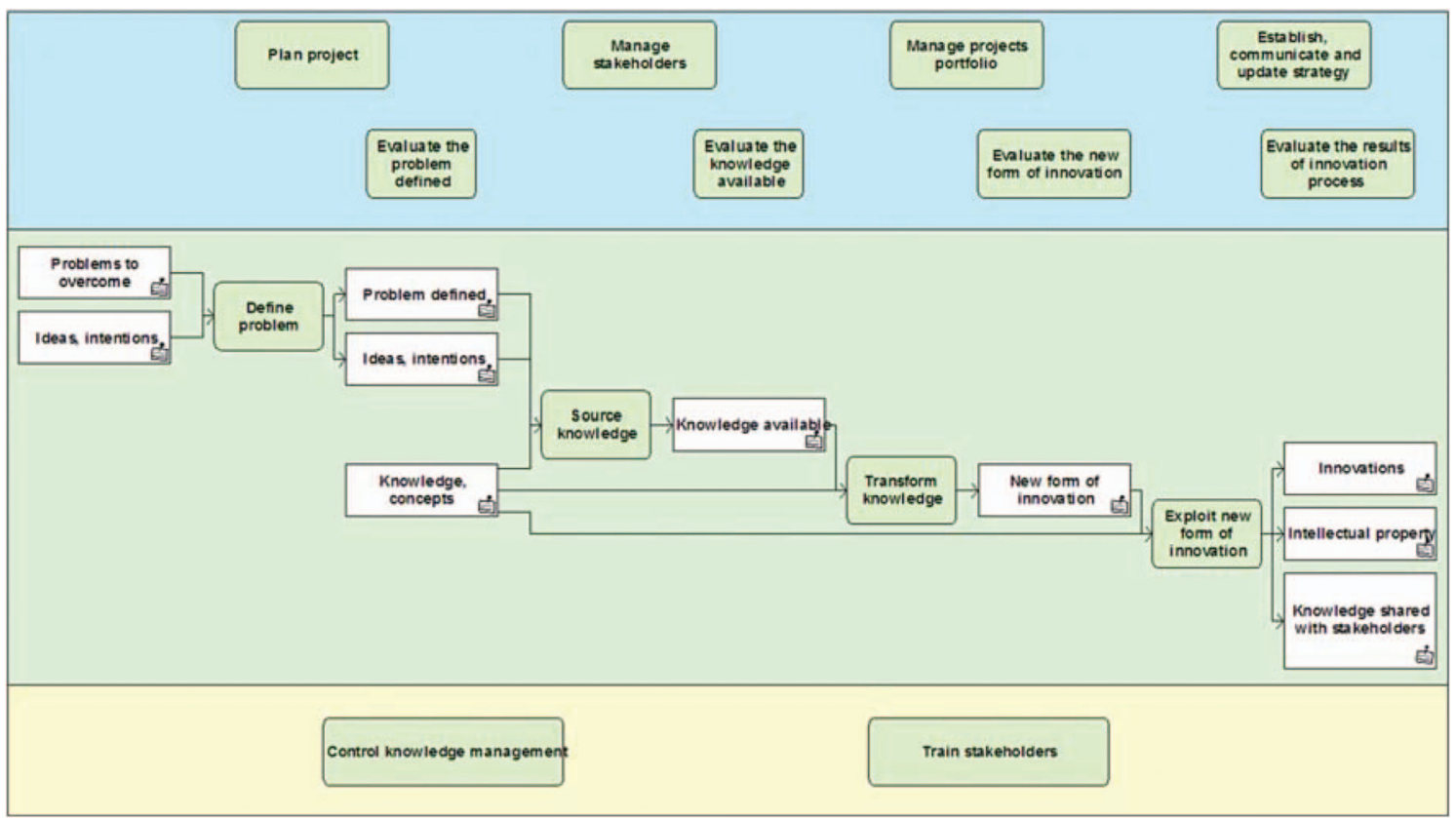

Figure 2. The innovation process. 
milestone of our innovation process that have to be modelled at a management level. Going beyond this purely functional view seems unrealistic, because there are necessarily many forms of stakeholders' behaviour and structural control activities depending on the context. The knowledge sourcing can be, for example, a permanent activity of the innovation process.

In a very minimalist approach of resources needed to support innovative process executions, it is needed to:

- Control knowledge management. Knowledge access is facilitated by controlling its storage, dissemination and access to share useful contents for operational activities.

- Train stakeholders so as to develop knowledge and learn a new skill.

Many classical activities of project management are reported on the process management part of this innovation process, because innovative projects are no more than a special case of classical projects:

- Plan project

- Manage stakeholders

- Manage project portfolio

- Establish, communicate and update strategy.

But other management activities are defined giving rise to the barrier that legitimates the idea of project specialisation. These activities are decision activities which are in connection with milestones and allow feedback loops within the operational activities of the innovation process. The analysis of the milestones helps understand these feedback loops.

The milestones of the innovation process are drawn in the lowest part of the management section. Milestones are considered as particular events of the process. Out of simplicity, we will talk about milestones either for the event itself or for the decisionmaking activity about this event. Milestones play a major role in process monitoring; they allow to evaluate the result of the previous operational activities and to make a decision on which activity must be or must not be executed next. We will describe each milestone of the innovation process in the next section.

\subsection{The milestones of the innovation process}

An operational activity is systematically associated with a milestone that enables to control and to run it. As previously explained, a milestone specifies whether the associated activity is successfully finished or not, and helps to decide what the 'way forward' is for the following activities. It is like a communication node through which the future of the project will be dynamically defined and decided. Consequently, four milestones are proposed in close connection to the four operational activities of the innovation process:

- Evaluate the problem defined

- Evaluate the knowledge available

- Evaluate the new form of innovation

- Evaluate the results of the innovation process.

To describe these milestones, an event-oriented language from the Aris toolset, the Event-driven Process Chain (EPC), has been selected. The EPC syntax is quite simple. The rectangles represent activities, while the hexagons are used to represent events triggering or ending activities. In addition, the circles represent logical operators. The circles with the symbol ' $\mathrm{X}$ ' mean the use of the logical operator 'XOR', while the symbol ' $\mathrm{V}$ ' represents the 'OR' and the symbol ' $\Lambda$ ' is dedicated to the logical operator 'AND'.

An example extracted from our case study of a breakthrough technological innovation will serve as a guiding thread in the following. It must facilitate the understanding of all possible scenarios that must be launched at each milestone.

The first milestone 'Evaluate the problem defined' comes after the operational process 'Define the problem' (see Figure 3).

Once the problem is defined, it is necessary to analyse the problem. Three scenarios may occur:

the problem is badly defined, so the process must be resumed from the beginning;

the problem is trivial, then it is not necessary to execute an innovation process. Simple solutions exist to this problem and there is no need to innovate. The diagnosis is that there is no innovation barrier and the project remains a classical one. Let us say that a standard research and development process can solve the problem; and

the problem is not trivial, so it is then essential to launch a more thorough study on the subject. The activity 'Source knowledge' can then be launched. There is a chance to have an innovation barrier.

The milestone 'Evaluate the knowledge available' follows the activity 'Source knowledge'. The activity 'Source knowledge' can lead to four scenarios as shown in Figure 4.

The aim of the activity 'Source knowledge' is to provide a knowledge content about the subject as well as its qualitative evaluation. If the impossibility to find 
knowledge on the subject is proved, either the problem is badly defined or it must end the process of innovation. Indeed, if the problem is badly defined, a feedback loop

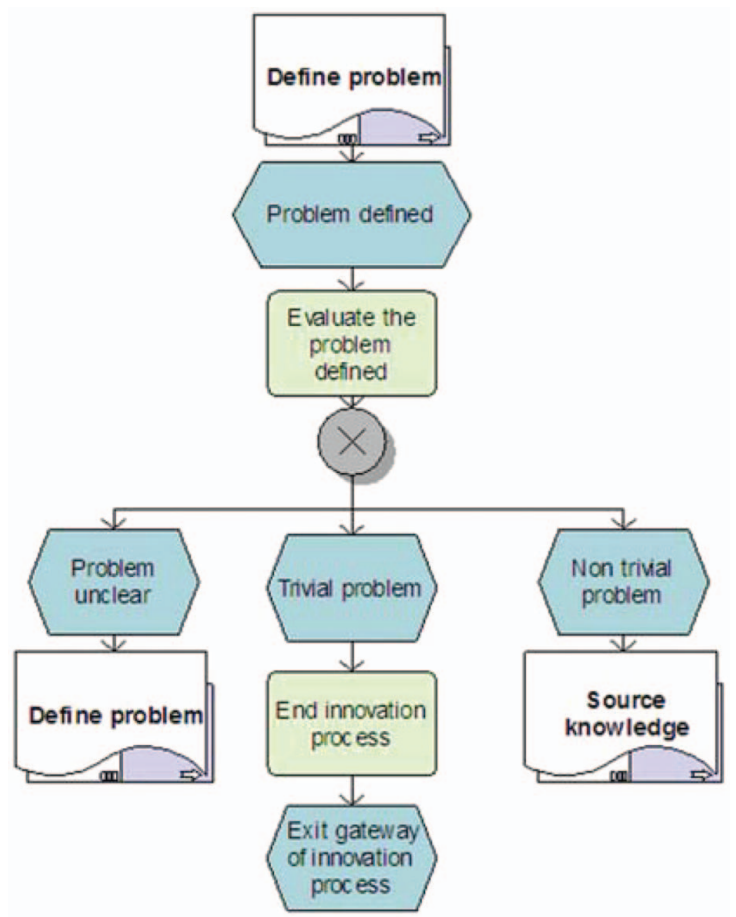

Figure 3. Milestone 'Evaluate the problem defined'. must be established to identify the problem more clearly. The activity 'Evaluate the knowledge sourced' appears to be of overriding importance. This activity assesses the completeness and the usefulness of the knowledge available. When the knowledge sourcing activity provides knowledge to stakeholders, either this knowledge can be sufficient to bring elements in order to resolve the problem, either it can be insufficient, or knowledge can be used to redefine the problem. In the first case, the activity 'Transform knowledge' can be triggered. In the second case, if knowledge is insufficient, it is necessary to 'Source knowledge' once again to obtain more satisfactory results.

Once the activity 'Transform knowledge' is completed, the milestone 'Evaluate the new form of innovation' is activated. It could be considered as a consistency check that will deliver information about the value of the new form of innovation, as shown in Figure 5.

Effectively, the process 'Transform knowledge' can give rise to a new form of innovation, and if so, assessing this new form of innovation technically and economically is important. This evaluation may lead to four scenarios. In the first one, the worst case is real, and the activity 'Transform knowledge' is unable to find a new form of innovation. This implies a feedback loop to the process 'Define the problem', or the end of the process of innovation because of a lack of results. The second scenario is triggered by a partial solution of the problem, involving a feedback loop to the process 'Transform knowledge'. The third scenario is

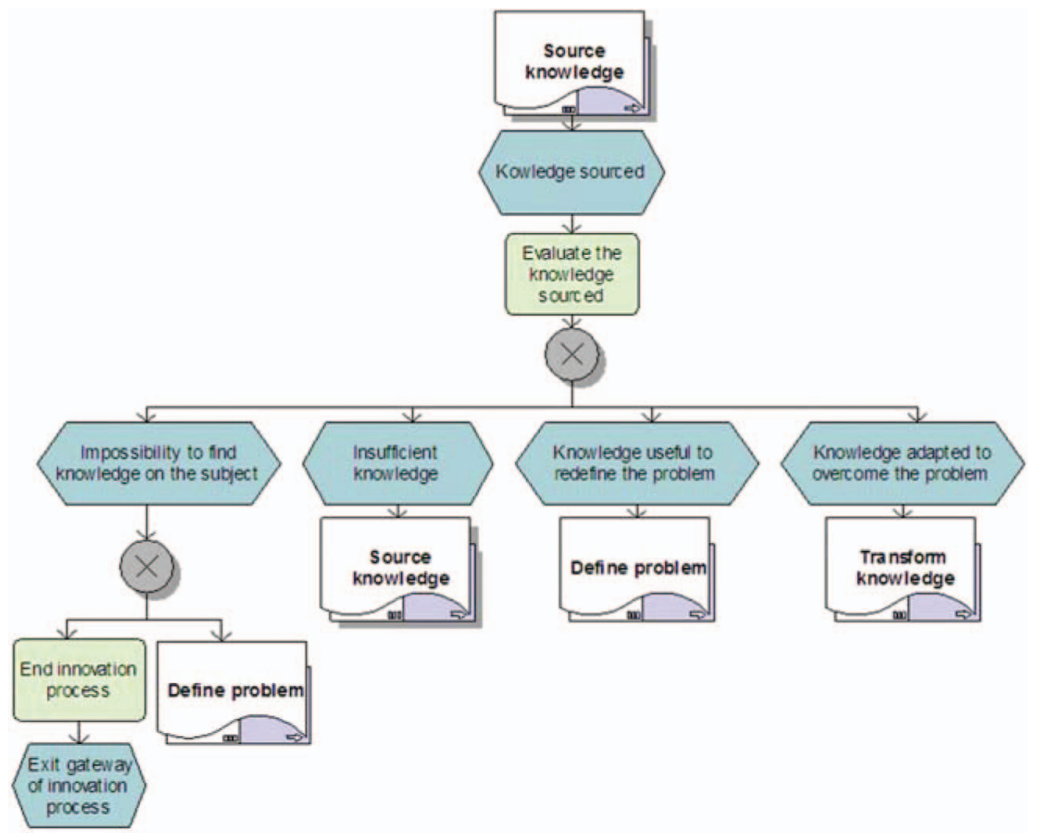

Figure 4. Milestone 'Evaluate the knowledge available'. 


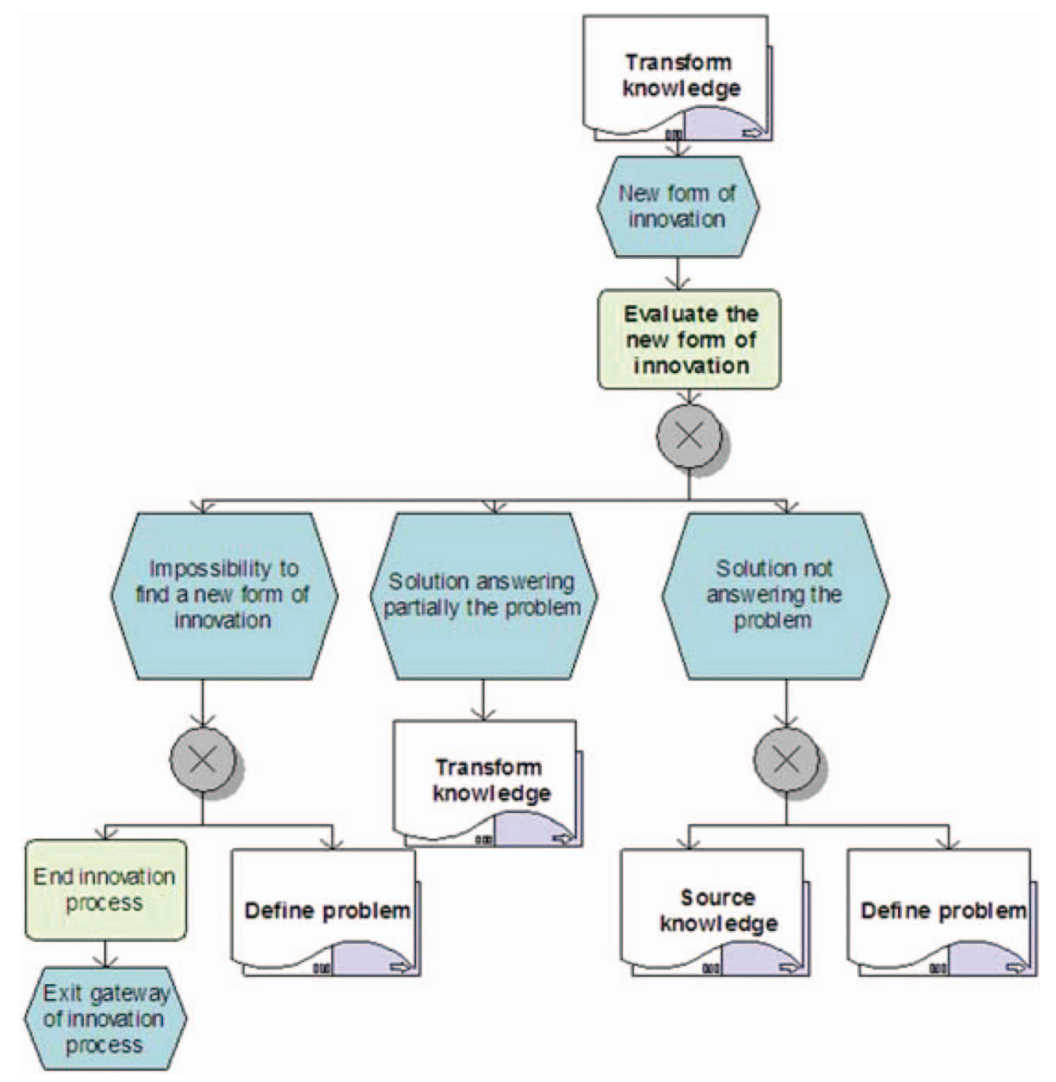

Figure 5. Milestone 'Evaluate the new form of innovation'.

the result of a solution that does not meet the addressed problem, allowing another feedback loop to the activity 'Define the problem'. The last scenario is a solution that perfectly meets the problem. A test should be done and the activity 'Exploit new form of innovation' has to be executed.

This activity is the last one of the operational part of our innovation process. A last milestone 'Evaluate the results of the innovation process' is attached and described in Figure 6.

Different scenarios are possible. When the innovation is commercialised with an appropriate intellectual property and with the new knowledge shared by stakeholders, the innovation process can end. This does not mean that the project has come to an end for the company. The company must keep working on the project, but it is no longer part of the innovation process. If it is not possible to exploit the knowledge transformed, feedback loops may occur to achieve the activities of the innovation process or, more radically, it can bring the innovation process to an end in case of major problems. This assessment consists in analysing the expected outputs of the innovation process that are not met and seeking the reasons for such failures.

\section{Links between practices and processes}

The literature provides a set of best practices promoting innovation or recurrent activities in innovative companies (Boly 2008). We propose to construct bridges between our modelling of the innovation process and some of these best practices that we want to integrate in our approach. Therefore, a preliminary study on the concept of practice and the kind of possible relationship with the one of process is necessary.

\subsection{Theoretical relationship between the concepts of processes and practices}

Deguil (2008) proposes a first definition of a practice as 'an application, an implementation of rules [ ... of o a science, a technique'. We must distinguish the rule ('prescription needed by someone in a particular case'), which gives a framework to the implementation of an activity, and the practice, which is the practical application of this rule. A practice is a way of doing things and executing an activity, respecting the specific rules of the field of this activity.

In a given industrial field, stakeholders have to face the same problems quite often, and therefore have to 


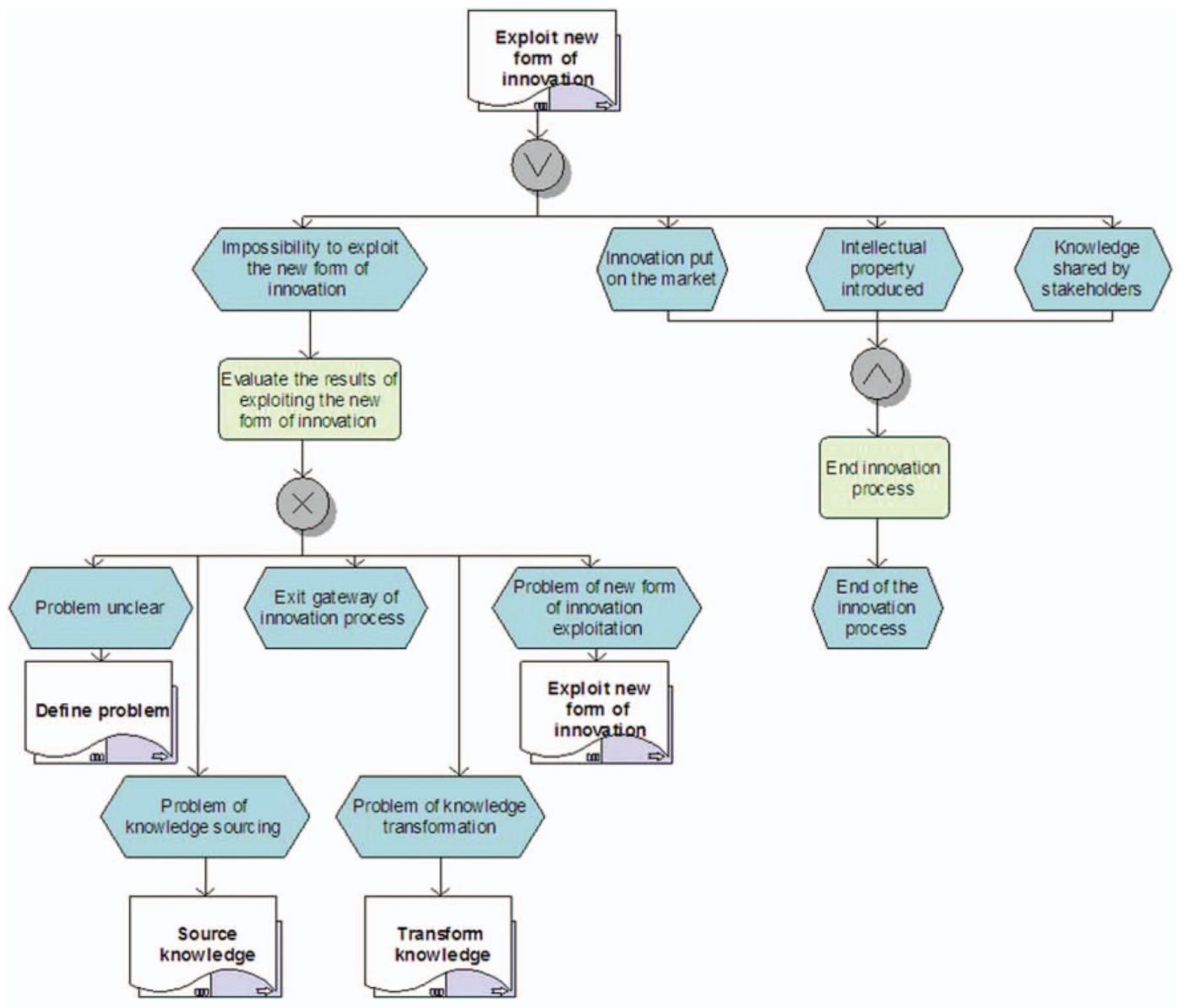

Figure 6. Milestone 'Evaluate the results of the innovation process'.

solve the same kind of problems. So, it seems appropriate to try and identify, the 'best way' to execute an activity or set of activities. This is, for example, the goal of a 'community of practice' (Wenger 2005). In this case, it is not a practice anymore, but a best practice. Deguil (2008) used a definition along these lines: 'the term best practice refers, in a professional environment, to a set of behaviours for which there is a consensus and which is considered as indispensable'.

A best practice is the result of a consensual analysis and of a feedback from past experiences. Giving importance to best practices is a pragmatic way to speed up continuous improvements in organisations. A mechanism of 'rule prescription' can be inferred and applied to activities.

The repositories of best practices are therefore proposing a package of 'expected activities' that have already demonstrated their efficiency and relevance in real conditions. For us, a best practice will be the pattern to execute an activity correctly, as illustrated in Figure 7. The formalism used is IDEF0.
Best practices are considered as recommendations that describe and 'guide' the execution of the activities. This vision is built directly from the Software Engineering Institute (2002), which states that a process is made of activities recognised as being driven through implementations of Capability Maturity Model Integration (CMMI) practices. These activities can be linked with one or more practices.

This relationship between practices and processes has to be studied as similarities existing between the semantic of processes and the definition of best practices. The words used to describe a practice can be similar to the ones defining an input, an output, a resource or a control of the activity associated. The reciprocal proposition is also true. To be comprehensive, controls and resources of our innovation processes are not described in this article and only general input and outputs are modelled. But looking at the practices is a good way to understand these four characteristics.

For example, our first operational activity 'Define the problem' is associated with two practices: 'Integrate 


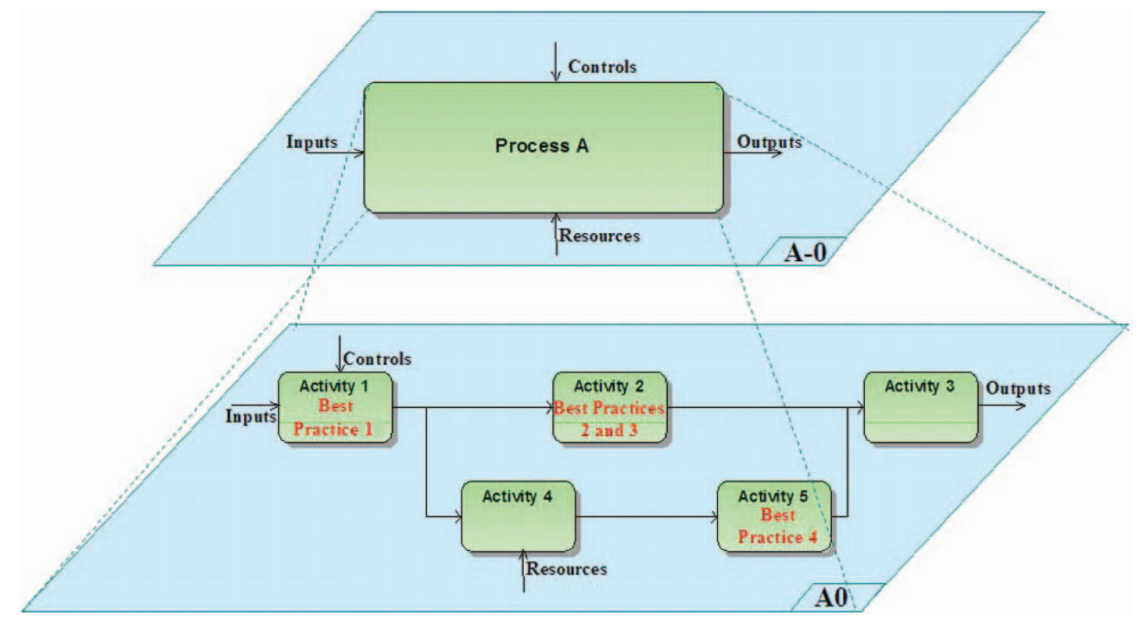

Figure 7. Representation of the relationship between activities and 'best practices' (Deguil 2008).

customers in discussions to define the problem' and 'Define the need to solve the problem'. In this analysis, wording 'customers' can be considered as resource of this process, and the 'problem defined' and the 'need to solve the problem' as outputs of this process, even if 'customers' and 'the need to solve the problem' are not described in our modelling. Similarly, practices can be considered as 'patterns' of processes. The best practices associated with each activity of the innovation process we propose are further developed in Section 4 (Table 3).

\subsection{Example of an application of this relationship in our study}

In the previous sections, we have proposed a reference frame with an innovation process and some possible links between this innovation process and practices. In this part, we are going to present the way of using them in order to promote innovation. We will show it through an example, from the industrial case we work on, and then generalise the approach. First, we describe the context of this industrial case, and then we illustrate the relationships we identify between business process model and our generic innovation process, based on a specific project of process development.

\subsubsection{Context of our industrial case study}

This research work is based on a pharmaceutical company. Activities of the company concern developing and producing pharmaceutical and health products (cosmetics and para-pharmaceuticals). The drug development process is composed of three main phases:

- the research phase which is concerned by hit generation activities, lead discovery, lead optimisation and the proposition of an active candidate;

- the development phase composed of clinical studies: Phase I, Phase II and Phase III; and

- the production phase to provide pharmacies and patients with drug by producing the active ingredient of the drug, by manufacturing the drug with other components and by packaging.

This process simultaneously concerns product development and production process development. The aims of studies and tests realised on the presumably active chemical or biological entity are to enhance the knowledge level of the future drug and to define the way both to obtain this chemical entity and to package the drug. A high level of novelty and complexity of chemical entities studied induces the need to develop innovation approaches to ensure that these projects success.

More specifically, the projects we analysed belonged to a unit located between research and industrial scale production of the product lifecycle. This unit is a required step through which every company's project must go. The 'product/production process' couple takes on a special meaning here. Indeed, the process development can significantly impact the way to obtain the product (choice of raw materials, purification methods, etc.). The work on the production process can have an impact on the final product. People involved in this process of development and optimisation are often very busy for accomplishing others operational activities. The execution and the expression of the innovation process suffer from this lack of time.

\subsubsection{Relationship analysis}

Let us assume that new chemical process technology is introduced as a way to solve a problem arising during a 
medicine project development. We observed several ongoing or finished specific projects in this context. $A$ posteriori for each project, a model was built to identify the real processes executed during the project life. In fact, the model design is done just before the last milestone (and so just before the end) of the innovation process.

Based on an analysis of these models, we note that the whole business process model has many similarities with the generic innovation process developed in Section 2. To understand how similar they are, a mapping between them is proposed. The aim of this mapping is to reveal the relationships between objects of the innovation process and of the business process model. We present in Table 1 the list of relations we proposed to establish between these objects. Each line of the table describes a type of relation which matches the description of a specific semantic link.

Table 2 gives an extract of the mapping developed. The links identified illustrate the relations between the objects modelled in the specific innovation process of the project analysed and the objects in the specific business process model of this project.

Based on the analysis of this mapping, it becomes obvious that the projects observed were exhibiting a real matching with the content of our innovation process. Such a perspective provides us some guidelines for managing the remaining part of the project life.

For instance in one of the projects observed, the new technology that was understood as a new form of innovation unfortunately appeared therefore useless. This means that the innovative solution was not successful during the first test of exploitation.

When this interruption was decided, the ongoing business process was naturally linked to the counterpart of an innovation milestone. Thus, time was given to the management to evaluate the situation (i.e. evaluate the results of exploiting the new form of innovation) and take a decision according to the

Table 1. Type of relationship between components of innovation process and business process.

\begin{tabular}{lll}
\hline Object in the innovation process & \multicolumn{1}{c}{ Semantic of possible relation } & Object in the business process \\
\hline Process/activity & Is initially executed in the process & Process/activity \\
& Is executed in the process & \\
& Is partially executed in the process & \\
Is finally executed in the process & Information \\
Information & Is described by by & \\
& Is partially described by & \\
Is finally described by & Document \\
& Is first described in & \\
& Is described in & \\
& Is partially described in & \\
& Is finally described in & Product \\
Is initially composed of & \\
Is composed of & Is partially composed of & \\
Is finally composed of &
\end{tabular}

Table 2. A partial view of the mapping between components of innovation process and business process.

\begin{tabular}{|c|c|c|c|}
\hline \multicolumn{2}{|c|}{ Object } & \multirow[b]{2}{*}{ Link } & \multirow[b]{2}{*}{$\begin{array}{l}\text { Object in the specific } \\
\text { business process model } \\
\text { of the project analysed }\end{array}$} \\
\hline In the generic innovation process & $\begin{array}{c}\text { In the specific } \\
\text { innovation process } \\
\text { of the project analysed }\end{array}$ & & \\
\hline Define problem & $\begin{array}{l}\text { Identify and analyse problem } \\
\text { area in the synthetic } \\
\text { pathway produced by the } \\
\text { research }\end{array}$ & $\begin{array}{l}\text { Is partially executed in the } \\
\text { process } \\
\text { Is partially executed in the } \\
\text { process }\end{array}$ & $\begin{array}{l}\text { Realise a preliminary } \\
\text { study } \\
\text { Produce the laboratory } \\
\text { batch }\end{array}$ \\
\hline \multirow[t]{2}{*}{ Knowledge transformation } & Assess synthetic pathways & $\begin{array}{l}\text { Is partially executed in the } \\
\text { process }\end{array}$ & $\begin{array}{l}\text { Perform tests to select } \\
\text { the final synthetic } \\
\text { pathway }\end{array}$ \\
\hline & & $\begin{array}{l}\text { Is finally executed in the } \\
\text { process }\end{array}$ & Produce the pilot batch \\
\hline
\end{tabular}


problem identified: Problem unclear? Problem of knowledge sourcing or transformation? Problem of exploitation? The management took the decision to end the innovation process, and at the same time, to end the project to develop the new technology for this active pharmaceutical ingredient.

But as seen in the previous section, this moment could also be the beginning of another innovation process. To understand what could happen, a screening of the best practices associated with the innovation process was performed. Such analysis quickly brought us to the conclusions that a new problematic could be defined by integrating the customer (see practice 1.1 in Table 3) and that defining the need to solve the problem was required (see practice 1.2 in the Table 3 ).

Executing business processes with such controls clearly provides many perspectives for managing project portfolios.

\subsection{Generalisation of this example: a new framework of alignment}

Our approach aims to align two process repositories in order to promote a proper management of innovation. In our example, innovation management was carried on aligning business processes on the innovation process using a set of best practices associated with the innovation process. Our alignment between business processes and innovation processes must be defined. Therefore, a general framework of alignment is provided by the alignment between business and information technology (IT) strategy. Indeed, the field of strategic alignment of IT is the most discussed and procures a lot of definitions. We decided to keep in mind a general definition of alignment provided by Sabherwal and Chan (2001) that describes alignment as the extent to which two or more organisational dimensions meet theoretical norms of mutual coherence. In our context, our two organisational dimensions are no longer business and IT but business and innovation. The alignment is effective if innovation best practices are used to define the way to execute business processes.

Henderson and Venkatraman (1993) describe the strategic alignment with their strategic alignment model (SAM), which is, according to Vargas et al. (2007), the most widespread and accepted conceptual model of alignment.

This model depicts the two different linkages between business and IT. The first linkage is called strategic fit and proposes that the IT strategy is an articulation of an internal domain (information system, infrastructure and processes) and an external domain (technology scope, distinctive competencies and IT governance). This strategic fit is also relevant for the business domain. The second one is called functional integration and links business and IT at a strategic level or an organisational one.

When we take into account the alignment definition from Sabherwal and Chan (2001), it is clear that it is possible to adapt this model to our alignment approach.

On the one hand, the business dimension is divided into a business strategy and an organisational infrastructure and processes. On the other hand, innovation is divided into an innovation strategy and an innovation infrastructure and processes. In our case, innovation strategy is defined by an innovation scope, distinctive competencies and an innovation governance. Infrastructure, skills and processes define the internal dimension of innovation. Figure 8 shows the relationships between these principles.

In the SAM, all the alignment sequences explained are the ones coming from the strategy to change the organisation or the processes. As explained in the previous example, we propose another alignment sequence coming from the processes to change the strategy. This specific alignment sequence is presented in Figure 9.

Our example illustrated in Section 3.2.2 helps understanding the proposed alignment sequence. This alignment starts from our innovation process considered generic enough to avoid changes. When the new technology is considered as innovative, the business processes of the project associated are modelled. This model represents our business process repository. In our example, the first step was to link the business processes and the innovation process using a mapping. This mapping is the support of the future alignment and was defined in previous publications (Penide et al. 2009).

The second step is to check if the business processes are really an innovation process. If it is the case, it is important to use the next milestone to prepare the alignment between the ongoing business processes and the innovation process. This alignment is finally supported by the set of innovation best practices that applies to our innovation process linked to the current and following processes. These best practices can then be used as 'patterns' of the ongoing business processes as explained in Figure 7. Finally, this alignment between business processes and innovation processes is a new way to manage business processes.

Our alignment sequence is supported by the definition of the functional integration between two process repositories. In this research work, we only consider the alignment sequence described previously, but other alignment sequences are also possible. For example, an alignment sequence using the strategic fit and aligning the innovation process and its best practices with the innovation strategy is a possible alignment. 
Table 3. Relations between the innovation process and the innovation best practices.

Innovation best practices associated

Operational processes

Define problem

Source knowledge

Transform knowledge

Exploit new form of innovation

Management processes

Plan project

Manage project portfolio

Establish, communicate and update strategy

Manage stakeholders

Supporting processes

Control knowledge management

Train stakeholders
1.1. Integrate customers (Boly 2008) in discussions to define the problem,

1.2. Define the need to solve the problem.

2.1. Search in past experiences of the company if a part of the solution has been tried or considered (Roper et al. 2008),

2.2. Generally speaking, provide knowledge to stakeholders and organise an awareness process, in order to open the company to external data:

2.2.1. Develop an awareness process on the subject until the end of the project (Boly 2008),

2.2.2. Search solutions from the competition (Roper et al. 2008),

2.2.3. Search solutions from the clients, the suppliers or the consultants (Roper et al. 2008),

2.2.4. Search solutions in conferences, symposium, universities, national projects or public research laboratories working on the subjects (Roper et al. 2008).

3.1. Test the technical feasibility of ideas for solutions,

3.2. Find a solution to solve all or part of the problem,

3.3. Evaluate financially and technically the solutions,

3.4. Select a solution that addresses the problem.

4.1. Check priority research of the possible solution,

4.2. Implement operationally, industrially and commercially innovation, involving the customer,

4.3. Protect innovation using intellectual property,

4.4. Make sure of filling and archiving of final closure documents or partial closure documents of the project, allowing a future feedback.

5.1. Allocate adequate resources to the project,

5.2. Providing a personalised project monitoring (budget, time, quality, innovative considerations), consistent with the strategic dimension driven by the direction (Boly 2008).

6.1. Organise the projects portfolio in order to have projects whose lifecycles overlap (Cormican and O'Sullivan 2004),

6.2. Manage the steering committee (Lenfle 2004).

7.1. Establish a clear strategy to promote innovation,

7.2. Split investments consistently with the objectives,

7.3. Communicate to the stakeholders involved in the innovation process the strategy of the company,

7.4. Update in a reactive manner the strategy and the objectives that result from it,

7.5. Direction must manage the technological networks in which the company is integrated (Boly 2008),

7.6. A feedback and a control of the innovation process by the management and the project leaders are necessary to make the practices evolve (Boly 2008).

8.1. A moral support must be provided to stakeholders by the top management and the project managers (Boly 2008),

8.2. Top management attention is directed towards the necessary competence allocation to the innovation process (Boly 2008),

8.3. Suitable context and working conditions are organised in order to stimulate innovation (Boly 2008).

9.1. Make good use of all sources of knowledge (adapted from Roper et al. 2008),

9.2. A collective learning approach is available all along the project (Boly 2008),

9.3. Specific tools for data management and collaborative work are developed (Boly 2008).

9.4. Know how and knowledge acquired during the former projects are capitalised in order to be reused for forthcoming projects (Boly 2008),

9.5. New ideas from research, marketing or propositions from the employees are continuously collected allowing to raise and to develop continuously new projects (Boly 2008).

10.1. Develop a training plan customised for each stakeholder of the innovation process,

10.2. Top management attention is directed towards the necessary competence allocation to the innovation process (Boly 2008). 


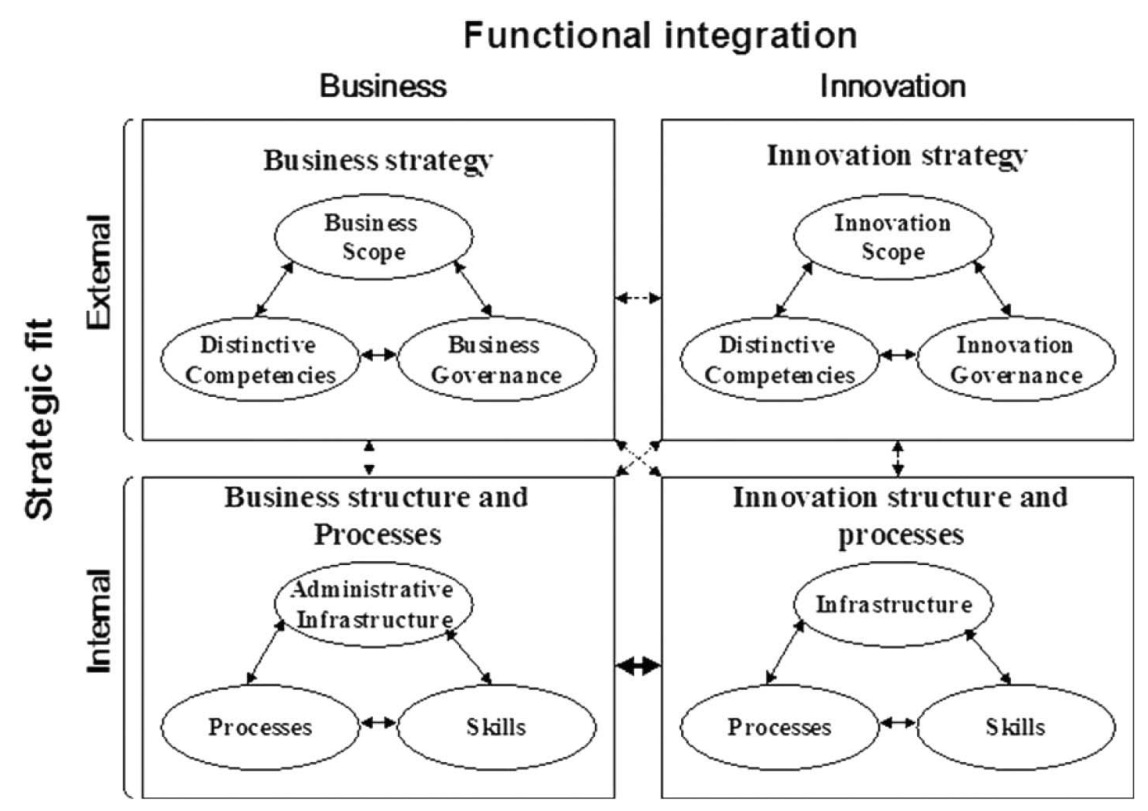

Figure 8. Innovation SAM.

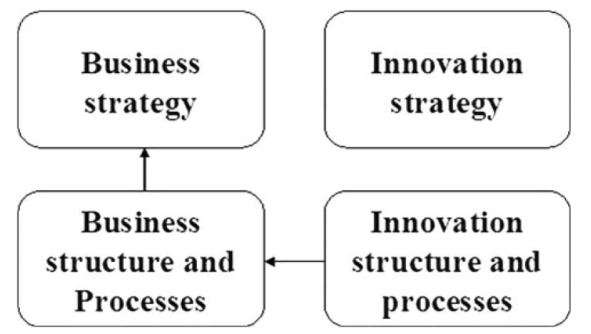

Figure 9. Our innovation alignment sequence.

In order to apply this new alignment methodology, it is necessary to explain the innovative best practices. This repository of practices, used as a pattern of business processes, will make the alignment possible in order to promote innovation.

\section{Practices promoting innovation}

\subsection{General statements about our innovation practices}

We started with the observation that our innovation process is very generic and should be supported by instructions for their good execution. The literature about the concept of practice and the relationship between processes and practices will also support our study. Each of our innovation processes, whether it is a management, an operational or a supporting one, is associated with several innovative practices. Each activity from our typical innovation process is linked with practices promoting innovation.

The practices presented in this article are inspired by a literature review strongly influenced by Boly's work (2008) and Roper's study (Roper et al. 2008). Boly (2008) describes 16 practices seen in innovative companies, whose analysis is based on an experiment in innovative enterprises from all business sectors and all sizes. This repository is seeking completeness and seemed to be a good starting point for our study. Nevertheless, it primarily discusses best practices associated with management of the innovation process. We have therefore decided to complete this repository, in particular with practices for the operational and supporting processes.

Our process is also based on the research work of Roper et al. (2008), explaining why their analysis of different kinds of knowledge is used in our best practices' repository. Some practices are then adapted from general work on innovation or on the innovation process written by Lenfle (2004) or Cormican and O'Sullivan (2004). Finally, some practices come from our personal analysis of innovation through the experimental field.

It is not possible to assure a priori of the completeness of this repository. But who can ensure the completeness of a repository of good practice, even a posteriori? However, we believe the whole innovation process is covered by the best practices, which were described as complete as possible.

Innovation being a major subject for the strategic development of a business, practices that foster innovation in the literature are predominantly focused on management and supporting activities of the innovation process. The pharmaceutical industry gives a sense to these practices, because poor management of 
the innovation process has led to a resurgence of mergers and acquisitions (Duflos 2007).

But this approach is applicable to any company of any field. However, innovation has to be seen through the prism of BPM. Our innovation process and best practices are general enough to be used by any innovative company. The repository of best practices can be adapted, should a manager want to focus on specific objectives.

In the next sections, we present each of these practices, classified by the corresponding activities whether they are operational, management or supporting. Practices inspired from the literature review are presented with the authors' references. Practices without citation result from our study.

\subsection{The operational activities and the best practices associated}

The first operational activity of our innovation process is 'Define the problem'. This activity is the beginning of the innovation process. Two good practices are presented here as compulsory steps for this activity:

- integrate customers (Boly 2008) in discussions to define the problem and

- define the need to solve the problem.

In fact, the customer integration is really important, even at the beginning of the process. The joint analysis of the problem with the customer can avoid many pitfalls in the early stages of the innovation process. Furthermore, this activity defines the need to solve the problem and forecast the difficulty.

The second activity involved in implementing the innovation process is the activity 'Source knowledge'. Good practices dedicated to this activity are:

- search in past experiences of the company if a part of the solution has been tried or considered (Roper et al. 2008) and

- generally speaking, provide knowledge to stakeholders and organise an awareness process, in order to open the company to external data:

- develop an awareness process on the subject until the end of the project (Boly 2008),

- search solutions from the competition (Roper et al. 2008),

- search solutions from the clients, the suppliers or the consultants (Roper et al. 2008) and

o search solutions in conferences, symposium, universities, national projects or public research laboratories working on the subjects (Roper et al. 2008).
The work of Roper et al. describes the different knowledge sources of the innovation process. This diversity of sources perfectly fits our vision of the innovation process and particularly our knowledge sourcing activity.

The next activity, 'Transform knowledge', can be defined by the following practices:

- test the technical feasibility of ideas for solutions,

- find a solution to solve all or part of the problem,

- financially and technically evaluate the solutions and

- select a solution that addresses the problem.

To transform knowledge, two testing practices should be implemented. The first one is useful to search the one that can address the problem among the available knowledge. This practice is useful to find valid solutions for all or part of the problem. Once the solutions are found, a second practice will give the chance to evaluate how the company can use each solution. Finally, the selection of the most appropriate solution must be performed.

The last operational activity of the innovation process is 'Exploit new form of innovation'. Four practices are linked with this activity:

- check priority research of the possible solution,

- Implement innovation operationally, industrially and commercially, involving the customer,

- protect innovation using intellectual property and

- ensure the filling and archiving of final or partial closure documents of the project, for future feedback.

These practices help to make sure that results of the innovation process are obtained. For this, an operational, industrial and commercial implementation must be made. A priority research should then focus on the originality of the solution found and help establish the kind of intellectual property needed. Finally, stakeholders should capitalise on the experience acquired during this project.

\subsection{The management activities and the best practices associated}

The management activities of our innovation process can be linked with practices the way we did with operational activities. For example, the activity 'Plan the project' can be associated with two practices: 
- allocate adequate resources to the project and

- provide a personalised project monitoring (budget, time, quality, innovative considerations), consistent with the strategic dimension driven by the direction (Boly 2008).

An individual planning for each project is necessary to provide good resources to the innovation process, but also to develop a personalised monitoring. This monitoring should allow responsiveness in decision-making and maintain consistency with the strategy and the objectives determined by the management.

In addition to an individual planning for each project, the activity 'Manage project portfolio' is proposed. The following practices are associated with this activity:

- organise the project portfolio in order to have projects whose lifecycles overlap (Cormican and O'Sullivan 2004) and

- manage the steering committee (Lenfle 2004).

Innovation is a key concept for the strategic development of a business. A coherent management of all the projects is essential for the future of a company. A portfolio of innovative projects, whose projects have lifecycles that overlap, avoids the company having seasonality effects in projects development. A good management of the portfolio requires the smooth functioning of the steering committee. Lenfle (2004) explains its missions: to check the validity of the assumptions on which the team works, to set the horizons of projects, to manage the projects succession, to launch new explorations in line with the other initiatives, and to support the strategic planning on concepts and crafts or to change the criteria selection of concepts.

To work on the company's strategy makes sense in the innovation process. The activity 'Establish, communicate and update the strategy' has to address this problem of consistency necessary for a proper functioning of this process. Several practices are associated with this activity:

- establish a clear strategy to promote innovation,

- split investments with the objectives consistently,

- communicate the strategy of the company to the stakeholders involved in the innovation process,

- update in a reactive manner the strategy and the objectives that result from it,

- the direction must manage the technological networks in which the company is integrated (Boly 2008) and

- a feedback and a control of the innovation process by the management and the project leaders are necessary to make the practices evolve (Boly 2008).

The management has to create a clear strategy to promote innovation. For more involvement, top managers can update regularly and communicate this strategy to the stakeholders. Furthermore, the investments and the objectives associated should be consistent with this strategy. The management must also control the networks in which the company is integrated. Finally, feedbacks from the management on the practices implemented lead to develop new ways of working in the innovation process.

Similarly, the activity 'Manage stakeholders' should be associated with three practices:

- a moral support must be provided to stakeholders by the top management and the project managers (Boly 2008),

- top management's attention is directed towards the necessary competence allocation to the innovation process (Boly 2008) and

- suitable context and working conditions are organised in order to stimulate innovation (Boly 2008).

If the management must support people involved in the innovation process, skills must also be clearly assigned to the stakeholders, in order to make them understand their role within this process. Some organisations have been recommended by Lenfle (2004): organisations clustering skills around a technique to explore its possibilities and its applications, organisations establishing a multi-expertise platform to explore an innovative design space, or organisations structuring an innovative team around emerging features of the product to develop products using new concepts. These organisations must be explained to stakeholders.

\subsection{The supporting activities and the practices associated}

The supporting activities of the innovation process also deserve an explanation of their content using practices. The activity 'Control knowledge management' is associated with the following practices:

- make good use of all sources of knowledge (Roper et al. 2008),

- a collective learning approach is available all along the project (Boly 2008),

- specific tools for data management and collaborative work are developed (Boly 2008), 
- know-how and knowledge acquired during the former projects are capitalised in order to be reused for forthcoming projects (Boly 2008) and

- new ideas from research, marketing or propositions from the employees are continuously collected allowing to raise and to develop continuously new projects (Boly 2008).

Checking the proper use of all knowledge sources must be done with the support of the characterisation of knowledge sources as provided by Roper et al. (2008). They identify five different sources coming from: R\&D being undertaken in the plant, forward knowledge linkages to clients or customers, backward knowledge linkages to suppliers or consultants, horizontal knowledge linkages to competitors or joint ventures, and public knowledge linkages to universities, industry operated laboratories or public laboratories.

The last activity, 'Train stakeholders', is also subject to an association with best practices:

- develop a training plan customised for each stakeholder of the innovation process and

- top management attention is directed towards the necessary competence allocation to the innovation process (Boly 2008).

The stakeholders must have a role to play, clearly predetermined by the management, and the skills of each stakeholder must be consistent with the role they play. Furthermore, a personalised training plan has to be established in such an innovative approach.

All these associations between innovation activities and innovation best practices are summarised in Table 3 .

\section{Lessons learned from the industrial case study}

The industrial field explored in this research work concerns the pharmaceutical development of a new drug.

Lessons learned can be classified into three categories:

- the relevant ones for business process and innovation process modelling,

- the relevant ones for innovation milestone modelling and

- the relevant ones for best practices' identification.

\subsection{Modelling process}

As far as the modelling activities are concerned, it is difficult to represent the operational part of an innovation process and it can even be dangerous. Indeed, giving a framework that does not fit real innovation can curb innovation. In order to avoid the loss of completeness, it is important not to limit the innovation process to some operational activities that are defined in a particular field. To remain generic to any type of innovation, we proposed to describe the operational activities at a relatively macroscopic level.

Our choice was to define the innovation process relatively close to the one provided by Roper et al. (2008) with processes that are described in the beginning of this article. These operational activities aim to be generic to any type of innovation. We added milestones, management and supporting activities to these operational ones. This new model of innovation process has been validated through some case studies of our experimental field. In this environment, we have studied a couple of projects related to new chemical entity development. The results of this analysis provided us with the basis of our innovation process model and especially highlighted the need of milestones to introduce loops in the process of innovation. These points were illustrated with extracts of our analysis of a pharmaceutical project in previous sections.

\subsection{Milestones modelling in the process development}

At the beginning of our example about innovation, our unit had to work on the development of a process for the production of an active pharmaceutical ingredient. This ingredient was used for a new medicine that was developed at the same time. After a first analysis, it seemed problematic to develop a common process because one of the vegetal raw materials was really hard to buy. In this milestone, the problem appeared clearly defined and non-trivial. It was therefore possible to source knowledge in order to solve the problem.

For the second milestone, knowledge was sourced in order to find a solution to the problem. The knowledge provided showed that a new production facility was a good possibility to internally deliver the problematic raw material, starting from classical low fare raw material. It was therefore possible to transform this knowledge to solve the problem.

At the third milestone, the new technology that was able to produce the problematic raw material was tested. The different tests showed that the technology was a good solution to solve the problem, at least at a laboratory scale. It then became obvious for the management that this new technology should be exploited.

Finally, at the fourth milestone, an external event changed the context. The development of the new medicine was stopped because of poor toxicology results. It was therefore useless to develop this technology, and this invention would not be an innovation. This was the end of this innovation process. But this new context led to another problem to face. How to make a 
profit on that new technology that we developed? This was the beginning of another innovation process.

Theoretical modelling of the innovation process could have been made by a simply linear process. The analysis of projects conducted us to explicitly describe milestones in order to capture the reality of lifecycle of this kind of projects and the decision-making process.

Explicit identification of milestone in the process allows decision-makers to propose tools for decisionmaking. The data necessary to make a decision in a good way can henceforth be listed at each step.

\subsection{Best practices' classification}

Practices identified in the literature review result from studies in different innovative activity domains. Based on our research work and the validation of experts of the domain that we solicited, such practices are fully applicable in the domain of pharmaceutical drug development. Based on the analysis of innovative projects in this domain, new practices have been identified to enhance the repository of best practices. The initial problem was limited to a specific department of the pharmaceutical company concerned by the development innovative production process. Thus, an analysis was made at a department level and it seemed that this choice was the good level. Modelling techniques allow to integrate process interfaces in order to correctly integrate the interrelation with other departments and links. So, today experts of the company have validated our propositions, and actual practices have been replaced by those proposed in this research work.

Alternatively, the practices linked with each activity of our innovation process can be of two kinds: (1) only valid in an innovative company or (2) valid in any business. For example, we can focus on the practice 10.2, which describes the need to have a clear approach for competence allocation to the innovation process. This practice is valid only in innovative companies. Instead, the practice 5.2 describes the requirement to monitor projects. This practice can also be found in a noninnovative company as one for generic drugs. However, this practice is a key one for an innovative company.

\section{Conclusions and outlook}

The innovation process is a knowledge transformation process, using appropriate resources and whose management holds an important place because innovation is strategic for companies. This article was used to model the innovation process as a non-linear process, punctuated by milestone activities that allow feedback loops.

A repository of innovation best practices mainly based on the work of Boly (2008) and Roper et al. (2008) has been proposed in this article. The relationship between the best practices and the activities of the innovation process helps clarify the required steps of each of these activities. This repository of best practices applies to our innovation process as to a repository of business processes. However, this model of innovation process is intended to be 'fungible' in a repository of business processes. Each element of the generic innovation process must be a 'tracker' to the elements of business processes that will be reported as contributors for innovation. Our approach will use a mapping of two process repositories, as theoretically defined by model morphisms in Deguil's work (2008). The deployment of this relationship will help link our innovation best practices with business processes as presented in this article. This mapping is briefly presented in another article (Penide et al. 2009), and will be the subject of future publications.

Future research work should aim to create a monitoring tool of the innovation process. This indicator scoreboard will make it possible to put indicators at each milestone of our process innovation. Using the process mapping mentioned above, the indicators can be positioned on the business processes corresponding to each milestone. The monitoring of innovations will be made on business processes but will also keep the pace of the innovation process.

This will foster innovation making the right choice at the right time. However, other tools exist to promote innovation and creativity in particular. Our approach is fully compatible with the other ones that promote innovation, such as:

- enhancing creativity with tools specifically made for this (TRIZ, brainstorming, etc.),

- working specifically on the strategic management of the innovation process (tools for portfolio management project, development of a culture of innovation, a posteriori analysis of innovations, etc.) and

- working on the supports of the innovation process (knowledge management tools, staff training).

These tools and methods to promote innovation are specific, focusing on some parts of the innovation process. Each manager can thus couple our approach with another more specific one, therefore improving one's chances to innovate.

\section{References}

Ben Rejeb, H., 2008. The front end phases of the innovation processes: proposal of an approach for the need analysis and the assessment of the acceptability of a product. Thesis (PhD). Nancy Université, Institut National Polytechni que de Lorraine, Equipe de Recherche sur les Processus Innovatifs, France (in French). 
Boly, V., 2008. Ingénierie de l'innovation: organisation et méthodologies des entreprises innovantes. 2nd ed. Paris: Hermès Science.

Chen, T. Y., Tsaih, D., and Chen, Y. M., 2010. A knowledge commercialised business model for collaborative innova tion environments. International Journal of Computer Integrated Manufacturing, 23 (6), 543564.

Christensen, C.M., 2003. The innovator's dilemma. New York: HarperBusiness Essential.

Cooper, R.G., 2001. Winning at new products. Accelerating the process from idea to launch. 3rd ed. Cambridge: Perseus.

Cormican, K. and O'Sullivan, D., 2004. Auditing best practice for effective product innovation management. Technovation, 24 (10), 819829.

Deguil, R., 2008. Mapping between a repository of require ments and a maturity model: theory and practice. Thesis $(\mathrm{PhD})$. Université de Toulouse, Centre de Génie Indus triel de l'Ecole des Mines d'Albi Carmaux, France (in French).

DiMasi, J.A., Hansen, R.W., and Grabowski, H.G., 2003. The price of innovation: new estimates of drug devel opment costs. Journal of Health Economics, 22 (2), 151 185.

Duflos, G., 2007. Innovation strategies and acquisitions in the pharmaceutical industry: empirical analysis. Thesis $(\mathrm{PhD})$. Université de Paris I, France (in French).

European Commission, 2008. European Innovation Score board 2007 comparative analysis of innovation perfor mance. Luxembourg: Office for Official Publications of the European Communities.

Galanakis, K., 2006. Innovation process. Make sense using systems thinking. Technovation, 26 (11), 12221232

Henderson, J.C. and Venkatraman, N., 1993. Strategic alignment: leveraging information technology for trans forming organizations. IBM Systems Journal, 32 (1), 416.

IDS Scheer, 2010. Aris platform. Available from: http:// www.ids scheer.com/fr/ARIS/ARIS_Platform/ARIS Design_Platform/30307.html [Accessed 3 September 2010].
Lenfle, S., 2004. Peut on gérer l'innovation par projet? In: G. Garel, V. Giard, and C. Midler, eds, Faire de la recherche en management de projet. Paris: Vuibert, 3554.

MacGregor, S.P., et al., 2006. Supporting new pro ductcreation in the Mondragon Valley. European Journal of Innovation Management (EIJM), 9 (4), 418443.

OECD, 2005. Oslo Manual. Guidelines for collecting and interpretating innovation data. 3rd ed. Paris: OECD.

Penide, T., et al., 2009. Représentation des processus en ingénierie d'entreprise innovante. In: sème Congrès International du Génie Industriel (CIGI'09), 1012 June Bagnères de Bigorre, France.

Roper, S., Du, J. and Love, J.H., 2008. Modelling the innovation value chain. Research Policy, 37 (6 7), 961 977.

Sabherwal, R. and Chan, Y.E., 2001. Alignment between business and IS strategies: a study of prospectors, analyzers and defenders. Information Systems Research, $12(1), 1133$.

Sienou, A., 2009. Methodological framework proposal for an integrated risk and business process management. Thesis $(\mathrm{PhD})$. Université de Toulouse, Centre de Génie Indus triel de l'Ecole des Mines d'Albi Carmaux, France (in French).

Software Engineering Institute, 2002. Capability maturity model integration (CMMI), version 1.1, staged represen tation. Pittsburgh

Vargas, N., Plazaola, L., and Flores, J., 2007. Constructing a general framework definition of the business and IT alignment concern through selected papers. In: 5th аппиаl conference on systems engineering research (CSER 2007), 1416 March Hoboken, USA.

Vernadat, F., 1996. Enterprise modeling and integra tion: principles and applications. London: Chapman \& Hall.

Weelright, S.C. and Clark, K.B., 1992. Revolutionizing product development. New York: The Free Press.

Wenger, E., 2005. La théorie des communautés de pratique, apprentissage, sens et identité. Laval: Les Presses de 1' Université Laval. 